At the tropopause there is generally an increase in the magnitude of the rate of fall (lapse-rate) of frost point with height; but this increase usually holds over a shallow layer only, and higher up the lapserate returns to the value it had in the upper troposphere. The increase in lapse-rate of frost point at the tropopause is most marked when there is an increase of air temperature with height there. Such an arrangement is characteristic of the tropopause above depressions and is believed to occur because the tropopause moves downwards over a depression. The subsidence of the air of the lower stratosphere necessarily tends to produce an inversion of temperature and a reduction of frost point. When the tropopause is marked in the vertical temperature curve by a reduced lapse-rate and not an inversion, the lapse-rate of frost point shows no tendency to increase there. This is characteristic of anticyclones and occurs because above them the tropopause is lifted up.

The humidity observations are analysed also for variation with season and air mass and the changes which occur on passing through a frontal surface.

The height attainable by the aircraft used for making the observations was not sufficient to enable them to climb into the stratosphere when the tropopause was above about 41,000 ft., and the results have some bias towards low tropopause. It is to be hoped that measurements of humidity to greater heights in the stratosphere will become possible in the future on a routine basis. The Americans Barrett and Herndon have flown an automatic frostpoint hygrometer to $100,000 \mathrm{ft}$. below a very large plastic balloon; but their apparatus (Compendium of Meteorology, American Meteorological Society, p. 1220 ; 1951) weighed $46 \mathrm{lb}$. Routine flights with balloon-carried apparatus must await the development of a lighter instrument.

\section{SOCIAL SECURITY AND UNEMPLOYMENT IN LANCASHIRE}

TNDER the title "Social Security and Unemployment in Lancashire", Political and Economic Planning has issued a useful broadsheet (No. 349 ; December 1, 1952) analysing the effects of unemployment on the working of the more comprehensive social security measures now in existence. The information was sought particularly from the cotton towns, and, although the survey is too limited to throw light on the adequacy of benefit and assistance payments, it confirmed the conclusion reached in an earlier broadsheet that actual patterns of expenditure by poorer families differ widely from that accepted as the basis of social security payments. Families appear to draw extensively on savings, and, failing these, economize on food and fuel to maintain certain types of expenditure, including even entertainment, as long as possible. The survey has shown that relatively few of the unemployed in Lancashire have applied for national assistance. This is partly due to ignorance or misunderstanding about the regulations, especially those concerning house ownership and the amount of savings which are to be disregarded in assessing need. Something less than half of those who would qualify for assistance seem ready to ask for it.

While on the whole the machinery of the scheme appears to have been put into motion quickly and smoothly, and regulations too have been administered in the spirit of the new Acts, the survey has shown that many people do not qualify for benefit, or qualify only for less than the standard amount. Most of the former are married women, and P F P makes the point that, when married women have to stay at home from time to time for such reasons as looking after their children or an invalid dependant, there is a strong case for relaxing the contribution conditions so as to enable more married women to draw benefit, either by crediting them with insurance contributions or by permitting them to continue contributions as if they were still in employment. Workers with secondary, part-time occupations are also in an anomalous position, and $\mathrm{PEP}$ suggests that the Ministry of National Insurance should review the regulations concerning subsidiary earnings in the light of recent experiences in Lancashire.

The evidence collected in Lancashire must obviously be interpreted with great caution for other areas; and PEP directs attention to the difficulty in making precise judgments about the working of the social services in Lancashire, because of the gaps in information which exist and the different methods by which the various official statistics are collected and presented. If for good reasons unemployment and national insurance statistics cannot be made comparable, it suggests that sample inquiries in circumstances such as those in Lancashire during recent months would provide evidence of material value to administrators and others concerned with the social services as well as to research workers.

\section{BREEDING BEHAVIOUR OF THE SWIFT}

$T$ HE breeding biology of the swift (Apus apus) has been studied by David and Elizabeth Lack (British Birds, 44, No. 6; June 1952). The first observations were made in 1946 on birds nesting in holes in thatched roofs in villages near Oxford; attempts were made later to induce the birds to breed in nest boxes. For many years swifts had nested in the ventilators in the tower in the Museum of Oxford and, in 1948, platforms were erected inside the tower and ventilators were replaced by nest boxes to which glass backs were fitted. The observers could now sit in semi-darkness a few inches from the birds, watching against the light from their entrance holes without causing them any disturbance. The paper describes the behaviour recorded.

Most adult swifts show little fear in their boxes, presumably owing to lack of natural enemies at the nest. There is, however, great individual variation. Some were extremely tame from the start and were not at all disturbed when, in weighing experiments, the eggs or young under them were removed and later replaced. Others at first left the box if a hand were inserted, but became tame through repeated handling. Some fiercely attacked an inserted hand with their claws, and displayed if noises were heard outside the box or objects seen near the glass.

The observations showed that each year about twenty pairs laid eggs, and several non-breeding pairs, possibly in their first year, occupied other boxes. The adults arrived in spring and departed in summer over about three weeks, the two members of each pair usually arriving and departing separately. Each pair normally rested in their boxes throughout the summer. 